\title{
Someone Like Us: Trades identities and support for work/learning
}

\author{
CHRIS HOLLAND
}

\begin{abstract}
This paper reflects on specific findings from a 2009 study of on and off-job learning that explored apprentices' learning experiences, formal and informal learning connections, and implications for language, literacy and numeracy in vocational learning. The study was conducted in the glazing industry in New Zealand, and as part of that study, apprentice profiles were developed. This discussion focuses on three of those profiles and reflects on two emerging themes. The first theme is employer and apprentice perceptions of the value of apprentices coming from a 'trades family'. The second theme is the range of inclusions and exclusions, advantages and disadvantages that apprentices experience depending on their 'trades family' status in both on and off-job learning. The paper then considers what kind of learning support might help integrate the different identities required within an apprenticeship.
\end{abstract}

\section{Introduction}

Over the last decade there have been many studies of factors impacting on learning on the job, and in both in-house and formal courses (see for instance Billet 2003, Billett and Sommerville 2004, Belfiore et al 2005, Kell et al 2009, Vaughan 2009). This discussion draws broadly on a series of qualitative research projects and associated development activity carried out between 2006 and 2010 in New Zealand for the Tertiary Education Commission, the New Zealand Council of Trade Unions (NZCTU), various New Zealand Industry Training Organisations ${ }^{\text {ii }}$ (ITOs) and their umbrella organisation, the Industry Training Federation (ITF).

The industries involved included transport, glass and joinery, hairdressing, and fire and rescue. The research explored both how people learn on and off the job, and learning support practices at work (Holland 2010, 2009, 2008, 2007a, 2007b). This paper focuses on three apprentice profiles that explore the relative advantages and disadvantages to learning afforded by identification with a trade prior to apprenticeship. The profiles consolidate data from other apprentice profiles developed during wider research and development work for the glass and joinery ITO in nine glass and joinery companies during 2008 and in six of the nine original companies in 2009. Questions for this paper are: 
1. What do employers who value apprentices who come from 'trades families' gain, or lose in the long run?

2. What advantage/disadvantage is it to apprentices if they come from a 'trades family'?

3. What are the implications for learner support?

\section{Nature of apprenticeships in New Zealand}

Modern apprenticeships in glazing involve 85 percent on-job learning (which includes a 16 module distance learning certificate) and 15 percent off-job learning in block courses. ITOs currently provide both internal and external support for trainees. In terms of external support, a large number of trainees working towards national certificates have access to training advisors, regional managers and apprenticeship co-ordinators.

However, women, Maori and Pacific people are under-represented in the industry and in the modern apprenticeship scheme generally. In 2003, females represented 6.6 percent of total modern apprenticeships, Maori people represented 14 percent and Pacific people represented 1.9 percent (McGregor and Gray 2003). Anecdotal reasons for low numbers of Maori and Pacific apprentices include institutional barriers, the difficulties many families have supporting apprentices on low wages, and the relatively few examples of Maori and Pacific trades people that aspiring apprentices can look up to. Efforts are being made within the tertiary education sector and within ITOs to attract under-represented groups into modern apprenticeships. All three apprentices profiled here were male, and they were either of Maori or Pacific ethnicity.

\section{Trades family apprentices}

The 2009 joinery and glass ITO study had set out to discover how learners were supported in on and off-job learning and about facilitators and barriers to learning. An emerging theme was that employers placed a higher value on apprentices who were known to identify with the trade prior to apprenticeship, or, as employers put it, came from a 'trades family'. In different ways, almost all of the nine employers worked with in the study revealed that they had learned over time to recruit such apprentices in preference over others. A 'trades family' is one where at least one member is, or has been a tradesperson. The actual trade other family members are involved in, seems to be less important than that they understand and value the trade world.

\section{Nature of workplace identites}

Billett and Somerville (2004) have written about how identities are constructed through engagement in the workplace, and how workplace cultures are also shaped by subject identities. A second theme emerging 
from these profiles was that the identities new recruits bring to the workplace also shape that engagement. Apprentices from trades families seem to begin their apprenticeship not on the periphery of a community of practice (Lave and Wenger, 1991), but already inside the trade community, in terms of cultural capital ${ }^{\text {iii }}$, employer recognition and employer preparedness to recruit. In exploring these themes, it emerged that the extent to which new apprentices are recognised as 'someone like us', seems to improve employer willingness to provide learning opportunities on the job.

However, analysis of the profiles also suggests that the very advantages afforded by an apprentice's trades identity at entry to his/her apprenticeship, may hinder his/her progress in off-job learning, unless he/she also identifies as a formal learner. Further, the analysis suggests that apprentices who do not bring a trades identity to the job may face barriers to inclusion on the job. The apprentices discussed here illustrate the inclusions, exclusions, advantages and disadvantages that seem to be a function of being able (or not) to draw on a trades background. The paper discusses implications for integrating apprentice support for both formal and informal learning.

\section{Research methods}

In 2008 and 2009 nine glass and joinery companies were visited on a regular basis to learn how apprentices managed on and off-job learning, how the two sites of learning were connected and how apprentices were supported at each learning site. Connections and interviews with managers about their experience with their current apprentices were facilitated by the Joinery ITO. Managers in turn offered time and space for research to be undertaken with their apprentices.

In order to learn more about apprentices' learning experiences and formal and informal learning connections, profiles of apprentices at six sites were constructed through on-job and on-course shadowing and interviews with apprentices, workplace mentors, supervisors, and course trainers. Three apprentices were observed and talked with in depth, in a range of circumstances: domestic glazing, commercial glazing and glass processing workplaces, and in one second year block course that several of the apprentices attended together. One apprentice worked for a small contractor business and two apprentices worked for large national glazing companies: one domestic and one commercial.

During the profiling period, each apprentice was visited between one and two days a fortnight in the months from February to April 2009, totalling seven days per apprentice. Job shadowing, observations and conversations, as well as more formal apprentice, supervisor and mentor interviews, all took place on these days. One of the three apprentices discussed here was job shadowed at his station in a glass processing factory, 
one was shadowed at various commercial glazing sites and the third was shadowed during several domestic glazing jobs. On-course observations and interviews (with these learners and their trainers) took place over three consecutive days during the middle week of the course. The final on-job interviews took place as a follow-up to the block course.

During job shadowing, apprentices were invited to talk through their tasks as well as any issues they had experienced and how they had overcome these issues. They were also invited to talk about their goals, thoughts and feelings about work practices (and later, the course). Additional, semi-structured formal interviews away from their work site invited apprentices to reflect on their experiences of learning on and off-site and on influences with regard to working in the glass trade. Finally, facilitators and inhibitors to learning on the job and on the course were explored through observations and interviews with the apprentices, and with supervisors, mentors, employers and course trainers.

Interview data were audio taped while notes were taken during discussions at work stations or on the road. The data were analysed qualitatively and cross checked for verification and checked against findings in the literature. Patterns, or 'regularities of behaviour or forms of interaction which occur over and over again' were explored (Altrichter, Posch and Somekh 1993:134). The aim was to identify emergent themes and patterns of response across a range of workplaces where apprentices were employed.

\section{Findings}

\section{The employers}

\section{Knowing the trade}

All employers interviewed seemed to have established fixed assessments of their apprentices' capabilities at the time of the research, which was in the second year of the apprentices' time. Some of the employers' assessments of their apprentices had been made through observation over time, others at recruitment, where a candidate's familiarity with the trade was expected to lend the apprentice an advantage. For example:

Take Glen. At sixteen, he's just out of school. But he comes from a 'trades family' and is already quite knowledgeable and keen.

We used to get apprentices who weren't up to it, but we are more careful with recruitment now. We prefer it if they know something about the trade. 
As will be shown in the apprentice profiles, coming from a trades family provides an advantage not only in terms of knowledge of the trade but also in terms of cultural fit.

\section{Apprentice profiles}

\section{Cultural fit}

The apprentices in the 2008 and 2009 glass industry studies learned safe workplace practices. They took pride in their workspace, whether in a factory, at a commercial site or in a van. However, they were expected to work at a fast pace and most seemed to be prepared to engage in unsafe work practices in order to meet the expectations of their co-workers. Taking the lead from more experienced workers, apprentices frequently took safety risks if it meant getting the job done more quickly and efficiently. For example, some would lift and carry a sheet of glass that would be more safely lifted by two people. Apprentices showed with pride lacerations to their bodies resulting from glazing accidents.

Cultural fit was as important on the course as it was on the job. The ITO used one glazing course site in New Zealand for all glazing apprentices so most apprentices travelled to attend the three week block course. The block course experience demanded concentrated classroom learning but it was the ability to fit in with the group during time off that won approval among classmates. As one apprentice stated:

The best part is not being at the [block course]. I would have liked to stay in [the city]. Some of us went in to [the nearest city] and had a good time.

\section{Apprentice learning}

The three second-year apprentices selected for this discussion range in age between 18 and 23, and I have called them Bryan, Andy and Pierre. They learn on the job every day, through watching, trial and error, and through instructions and warnings given by others. In addition, they are required to complete one three week block course a year, and a 16 module distance learning certificate. Distance learning requires that trainees complete a number of self-paced learning workbooks, and that they complete distance assessments. Vocational course learning occurs in trade classrooms (with work benches, machinery, tools and desks) involving same year apprentices brought together from all around the country. Apprentices' coursework is divided into three sections: theory, calculation and practical, and they are tested every morning on the theory and calculation they learned the previous day. 


\section{On the job}

Bryan tells me he is a boy racer as the company van squeals out of the site onto the road. He comes from a 'trades family', and his father, Hemi, is a senior tradesman at another glazing site. This gives Bryan a degree of cultural capital in that he knows what to expect in a trades environment and what is expected of him. Bryan fits in well with the workplace culture, is quick to learn and keen to be independent of his father. Bryan is confident about his knowledge of the trade and of his ability to achieve success. In the van he reviews his job sheets, calls customers on his cell phone, makes appointments, reads maps and locates job sites and rationalises the route for the day (all while driving). Once at the domestic repair site, he estimates job costs, carries out repair work, and prepares invoices and receipts. He is proud of his level of responsibility and enjoys the challenge and opportunity of interacting with customers and making onthe-spot decisions about jobs and pricing.

Having sole responsibility for a company van is unusual for a second year apprentice, and this underlines the company's trust and confidence in his work. He in turn keeps his van tidy, makes special storage compartments and develops other time and space saving improvements. Bryan has a passion and commitment to his work, identifying with the organisation's goals and working to enhance his own practice. But he is also prepared to take shortcuts, as more experienced tradesmen do, such as handling glass without gloves.

Bryan is able to identify what he needs to know and has sought support from a tradesman at his workplace, who has allowed Bryan to watch him working in areas where the apprentice does not yet have experience. For example, Bryan has difficulty with some pricing and is now able to work out prices with the aid of a matrix provided by the tradesman.

Andy is conscientious, reflective and deliberate. He does not come from a trades family but from one involved in formal learning - his mother is a teacher. He works with two senior tradesmen and another apprentice. Andy is unsure of how things should be done and is often anxious on the job, frequently asking what he can do next to be helpful. He works carefully, with much attention to detail. His employer has little patience with Andy; from his point of view the apprentice is not doing things the right way. He is teased. Andy attempts, with varying success, to return the teasing of his employer, but these efforts are inappropriate in their eyes. $\mathrm{He}$ asks a lot of questions because that is how he is used to learning. These behaviours appear to his employer to indicate uncertainty, and so Andy is not trusted to work without supervision and all decisions about equipment, tools and materials are made by the senior tradesmen. Andy is seen as 'slow' and a drawback when work has to meet deadlines. He is expected to 
act more independently, but does not realise this. He is aware of how people react to him, but unaware of cultural gaps. He asserts he is gradually becoming one of the tradesmen and that he has learned a lot on the job. He reflects on his learning and is continually seeking opportunities to solve problems, and to learn new skills.

Pierre is 23 , and moved to New Zealand from a Pacific Island six years ago. He is married with young children. Although he is quite a fluent English speaker, he is shy and quietly-spoken. He is not familiar with the cultural environment of the glass trade in New Zealand and is confused at work. At first he was put out on the road with senior glaziers, but didn't cope well - little was explained and little of that made sense. He does not assert himself, but instead begins arriving late for work. This causes the supervisor to place him permanently in the factory. He works at the same table every day, lining up and machine cutting glass, trimming it, loading scrap into bins, emptying the bins and sweeping the floor. His supervisor promises that at some stage he will be moved to other parts of the factory to learn how to do new tasks. However, the supervisor is also clear that he finds that having to supervise and look after Pierre as an apprentice glazier is a burden. He says he would prefer to replace this apprentice with a cheaper labourer. Pierre learns very little in the factory as there is no variety, but is helped a little by a fellow countryman who works on the shop floor. The man was once a supervisor in this factory but left, and when he returned the supervisory position had been filled. He shows Pierre how to do tasks on the job in between his own work commitments but is given no dedicated time to work with Pierre.

\section{Block course and distance learning}

If we look at how Bryan, Andy and Pierre cope with different spheres of learning, we see that having a trades family background is helpful for understanding and adjusting to the culture of the workplace and for on-job learning opportunities and progress. It is less helpful, however, for off-job learning, where a formal learning culture prevails, and where literacy and numeracy are called upon in ways not required in the workplace (for example reading/calculating to learn rather than reading/calculating to do). It is also less helpful for self-directed distance learning, where a measured strategy is needed to identify and deal with difficult areas of learning and to complete all the modules within the expected time frame.

Bryan enjoys the social side of the block course, while still competing to finish the twelve practical projects before the others. Although his speed and self-reliant approach seemed to work for him on the job, difficulties with listening, reading, studying and completing reports does not serve him well here. He says: 
My first course I did it quite well but in this one my timing was pretty out. In my second week I over-estimated, I should be able to do this many, first week full on second week laxed out and third week, shit, so no I didn't really crank it this time.

If I did a project and something small went wrong and I didn't have time at the end to repeat it I would just hand that one in and that would do. It was hard for me to do those reports. It's just annoying, remembering what you do and writing it down in detail, step one to nine.

Ten minutes before the test they give you to look over the notes, that's all I did.

Bryan's physically active and speedy approach is also unhelpful for completing his 16 module distance learning certificate, where hours of disciplined engagement in reading and writing are required. For the distance learning modules, Bryan was fortunate for the first six months of his apprenticeship to have had a company appointed mentor to support him. The mentor, an office administrator, supported him to complete five modules, but since she left, he has gone no further.

For Andy, the reflective, careful, double-checking behaviours that negatively impact on how he is perceived on the job, work well for him in distance learning and on the block course. He has developed excellent time management with distance learning, downloading his workbooks and assessment papers, locating information and sticking to his study times. Andy explained:

I do the theory side of it at home in my own time and when the book's finished I go to Craig and he signs it off. I just have to make sure that I go over the books and do them. I suppose you just have to get into a routine.

Although he has not been briefed by his employers about what to expect on the course, he is comfortable in a classroom-like environment, and asking questions of the trainers gets a positive response. He can cope well with problems on paper that are isolated from their physical context. He has developed a learning strategy, so he does well with reports and in tests:

I found it easy to write the reports after I learned, myself, to take a couple of notes while I was making the projects. So as I'm making the projects I quickly make notes of what I did step 
by step and re-wrote the report at night in such a way that the tutor wanted it.

I reckon time management is really important just for the simple stuff like putting your projects together and that. I saw a lot of guys dicking around and then they are surprised that they didn't finish all their projects.

I think you can tell who does well in the tests because they sat down and went over their notes. The people who didn't do well in their tests didn't do the preparation. Cos it's pretty simple it's easy to pass. All you need to do is go over your notes.

In practical work he takes time to watch others and he double checks his own measurements. He achieves very high results in the class. This surprises the senior tradesmen and causes them to review their assessment of Andy:

Everybody thinks he's not the full quid but I don't think so, sometimes.

Pierre has not begun his distance learning modules, nor has he been offered any help with them. He has no idea where to begin. He is not briefed about the vocational course, and asks me what he should take. He struggles with his coursework, especially the written components, as he has difficulty with reading and writing in English. He is not confident asking for help from tutors, but has initiative to ask for help from his fellow students on the course. Some give him their project reports to copy and help him with practical work. He admits:

I got help from other guys. It was OK, I copied. Got lost with theory. Just copied what he wrote on the board. Only the beginning made sense and then I got lost when it came to writing down the (calculations). I just wrote down what I remember.

However, this kind of help does not improve his understanding and builds resentment among some students.

\section{Someone like us}

Bryan's employers recognise someone like themselves in the apprentice. In turn this helps him make progress with work (he is given his own van in his first year as an apprentice) and with learning on the job (he 
can access appropriate support). Bryan understands expectations of the trade and his role in it, and quickly makes sense of job sheets. He is able to communicate effectively with contractors who call to pick up glass orders, problem solve, measure and calculate glass sizes and completion times, plan jobs and solve problems. The knowledge that Bryan brings to his apprenticeship wins him approval, inclusion and greater independence on the job.

Success in formal courses requires a different set of values, dispositions and behaviours. In formal learning, learners are required to demonstrate disciplined behaviours linked to school learning - they are required to sit for a period of time listening, reading, discussing and reflecting on what is being taught. They have to study and retain written information, construct written reports and pass tests. Thoroughness, perfect finish and safety are valued on the course, rather than speed and efficiency. All these formal learning expectations run counter to Bryan's identity as a tradesman who typically identifies and solves practical work problems at speed through talking and doing - and then moves quickly onto the next job.

Andy brings no identity as a trades worker and this is demonstrated in his nontrade approach and behaviours. His reflective skills, his critical thinking and questioning annoy his employers, and he somehow misses the mark with on-job banter. Unlike Bryan, he is not well able to identify what he doesn't know in terms of the culture of the workplace, and there is noone to support him with this and to help him access a wider range of job skills in order to practice, build and demonstrate competence.

Andy's employers form an opinion of him as mentally slow and limit his opportunity to practice his emerging skills on the job. He is given little opportunity, for instance, to greet customers and discuss the job with them, to complete job sheets, and to measure spaces and panels. Although Andy brings no identity as a trades worker he does identify strongly as a student and copes well with formal learning. He succeeds markedly at formal learning, and the perceptions of his employers are changed towards him. He also succeeds with distance learning and now in his second year, he has completed eight modules unassisted.

Pierre does not identify either as a trades apprentice or as a formal learner. He struggles with written language, with course expectations, with the culture of the workplace, and with the different cultural expectations of New Zealand. He has not begun his self-directed distance learning modules and is not aware that they need to be downloaded from the internet. Pierre is the apprentice who would most benefit from learning support in the workplace to address the multiple barriers he faces, yet he is least able to access support in his current job, which in any case has been reduced to a minimal amount of measuring and job sheet checking, by a supervisor who 
has made up his mind about the apprentice. Pierre knows he needs significant help in all areas and also that that help won't come. He just wants to keep his head down and hold onto his job, in order to provide for his family.

\section{The advantages/disadvantages of coming from a trades family}

Much research has identified the importance of conceptual knowledge such as understanding the bases for work tasks, and learning the 'tricks of the trade' (Billett, 2000). These profiles suggest that those who come from a trades family may have an immediate advantage in terms of knowledge of the trades world. Bryan was recognised as a trades identity immediately and given opportunities to develop quickly. The profiles also suggest that trades family apprentices may lose some of this advantage on the block course and with self directed distance learning, and so these aspects of their trades identity need to be strengthened. For those with no trades identity, it is cultural knowledge that needs building. Andy, unfamiliar with the trades world, struggled at first with communicating effectively and with the expectations of tradesmen. He needed guidance to adapt to the new environment before finally earning respect through high performance on the block course. Pierre had many barriers to overcome on the job and on the course. Guidance and support could have made a big difference to this apprentice and to his ability to win the respect of his supervisor.

\section{Supporting apprentices}

Each of the profiled apprentices had recognised the need for such support and had tried to get help. But what was actually available to Bryan, Andy and Pierre? None of the apprentices were given adequate support by their employers, although of the three, Bryan had the most support. Bryan and Pierre were prepared to seek out help but Andy tried to manage on his own resources.

In terms of on the job mentoring, Bryan called on a tradesman for advice who invited him to watch and assist with new and complicated tasks. Bryan also had effective, ongoing mentoring for the distance learning modules in in-house classes run by a woman in the office until late 2008, and had completed assessments for five workbooks during that time. $\mathrm{He}$ wishes he could have a return to the 2008 classes:

[I could do] some of them, but it's sort of like the work down at the block course aye. You sort of need someone to show you. The guys at tech, most all of them got given the workbooks. 
When I told them that I had a class for it, used to, three days a week, go upstairs for an hour, they couldn't believe it.

On the job Andy seems at first to be luckier than Bryan, in that he has two senior tradesmen /employers who are constantly explaining the intricacies of the work as well as what is expected of him as an apprentice, but he's unluckier in that the relationship is very hierarchical and the tradesmen don't trust him to do anything without their tight supervision. Andy is also lucky to have a discipline for study that brings rewards. Perhaps the new respect felt by his employers following Andy's block course results will bring in a change of employer practice, as he clearly demonstrates a need for a supportive mentor on the job.

Pierre carries out his limited daily tasks competently. It is possible that with more time his co-worker might have made a positive difference for Pierre, but he was blocked from providing assistance to the apprentice by the new supervisor. Pierre is not helped by anyone at his workplace to understand the requirements of his coursework or distance learning modules and he is unable to begin his self directed study without assistance. He asks people for help indiscriminately. Very uncertain about all requirements related to the certificate and learning on his apprenticeship Pierre asks me for help in getting information. He is in desperate need of a mentor who can help him negotiate both on and off-job learning requirements.

\section{Employer value judgements}

While employers seem confident that employing an apprentice from a trades family is all that is required, these stories seem to indicate that focused support needs to be provided to enable trades family apprentices to extend their trades identities so that they encompass not only on-job learning, but also off-job and distance learning. The judgements made by employers about apprentices who do not come from a trades family tend to be hard to shift, yet these judgements may hold back great potential. For apprentices with non-trades identities at the start of their apprenticeship, more support is needed to help them understand the culture of the workplace and to develop their own trade identity.

\section{Implications for learner support}

\section{Mentoring}

The 2009 research in the joinery and glass industry showed that there was little connection between on and off-job learning and little support given to apprentices to prepare them and help them through off-job learning. The research also found that where there was support, apprentices made significant gains in achievement towards their national certificate. In 
several New Zealand ITOs mentoring is receiving greater attention as a means of assisting apprentices to complete their apprenticeship and national qualifications. The training agreement between the glass and joinery ITO and employers specifically states that apprentices should have a workplacebased mentor, however, this requirement was not audited at the time of the research.

The recommended model of mentoring by the glass and joinery ITO is a relational model, consistent with a social capital approach, where the learner is regarded as a valued equal who happens to have specific support needs, and where issues of respect and trust play a larger part. The relational model is regarded as the 'highest quality mentoring state' (Ragins and Verbos 2006:21). It is also consistent with a Maori model of mentoring, or Awhina, which is closer to a befriending of the mentee (Ratima and Grant 2007:4). In relational mentoring the mentor is proximal and the relationship is not hierarchical - Bryan and Pierre looked for such mentors. Vaughan (2008) and Billett (2003) note that while the responsibility for mentoring may be held by one person, it may also be distributed among several people. Again, Bryan and Pierre sought help from more than one person. McManus and Russell note that 'Repeatedly, researchers have suggested that individuals who have multiple sources of support fare better than those who do not'(2007:294).

Recent research (Holland 2008, 2009, 2010) has shown that workplace mentors can include people who do not have trades skills but who can help apprentices to manage their time, understand all the study requirements of their apprenticeship, prepare for new learning before each block course and complete qualifications. Such people might be drawn from administration, where the mentor has no hierarchical relationship with the learner. Administrator mentors can also discuss course progress and further development on their return to the workplace. Such a mentor supported Bryan for a time, and might well have supported Pierre, whereas Andy would have benefited from on-job support provided by a more experienced co-worker.

\section{Summary and conclusion}

I have presented profiles of three apprentices taken from research carried out between 2008 and 2009 and drawing on broader research carried out between 2007 and 2010 in a range of New Zealand industries. The profiles are of apprentices involved in three areas of learning: on-job, offjob block course and distance, and they show how different advantages are afforded to apprentices coming from a trades family in terms of on-job learning. These advantages may not be attributable to real advantages a trades family identity gives the apprentice, but to the assumptions employers make about such apprentices. The perceived advantages do not 
necessarily follow through to formal block course and distance learning, because these modes of learning demand a different, formal learning identity.

The study examined the identities of glazing apprentices, associated with masculine competitiveness, self reliance, physical activity and risk taking. It showed that the apprentice from a trades family more strongly identified with these characteristics, and more easily integrated into the culture of the trade workplace, thus facilitating learning on the job. It further showed that the apprentices who did not come from a trades family had more difficulty with employer perceptions of their potential and with on-job learning. Where one apprentice was able to balance this disadvantage with success in formal learning, the other apprentice suffered from a double disadvantage in that he struggled to cope with on and off-job cultural expectations and learning requirements.

These findings highlight the difficulties faced by non-trades apprentices, many of whom are Maori and Pacific apprentices. Such apprentices in glass, joinery and other trades are less likely to come from a trades family, since their older family members are less likely than Pakeha apprentices to have been employed in the trades. Further exploration into the barriers faced by Maori and Pacific apprentices, and by women in modern apprenticeships, is required.

Bryan, Andy and Pierre showed that mentoring was able to make a difference in on and off-job learning. Bryan was supported with his distance learning components, but this support was withdrawn early, and he was unable to complete modules unassisted. Pierre was supported for a short time with on-job learning by his co-worker, and in off-job learning by fellow students. Andy was not mentored at all. He had no real support from his employers who judged him because he didn't fit the typical profile of a glazing apprentice. Fortunately, he possessed his own resources for managing study and was eventually able to win some employer confidence through demonstrating success in off-job learning.

An analysis of the three apprentice profiles was not able to determine whether or not mentoring could change fixed employer perceptions of apprentices (including negative perceptions of recruits who do not identify with the trades and overly positive perceptions of those who do). But it does seem to suggest that mentoring might go some way towards integrating the development of on-job and off-job learning identities.

\section{References}

Altrichter, H, Posch, P and Somekh, B (1993) Teachers Investigate Their Work: An introduction to the methods of action research, Routledge, London. 
Belfiore, M, Defoe, T, Folinsbee, S, Hunter, J and Jackson, N (2004) Reading Work: Literacies in the new workplace, Lawrence Erlbaum, New Jersey.

Billett, S (2003) Workplace Mentors: Demands and benefits, Journal of Workplace Learning, vol 15, no 3 ,pp 105-113.

Billett, S and Somerville, M (2004) Transformations at Work: Identity and learning, Studies in Continuing Education, Volume 26, Issue 2, pp 309-326.

Holland, C (2007a) An Exploration of Trainers' and Trainees' Attitudes to ITO Training Support in the Road Transport Industry, Tranzqual Industry Training Organisation, Wellington.

Holland, C (2007b) Report to the Fire and Rescue Service Industry Training Organisation on Training in the Rural Fire Service, Fire and Rescue Industry Training Organisation, Wellington.

Holland, C (2008) Under No Illusion: A research report into vocational tutor learning and practice in embedded literacy, Prepared for the Hairdressing Industry Training Organisation and the Tertiary Education Commission, Wellington.

Holland, C (2009) On and Off the Job: Learning experiences, connections and implications for LLN, Report for the Joinery and Glass Industry Training Organisation, Wellington.

Holland, C (2010) Survey of Mentoring in Volunteer and Combined Brigades, Fire and rescue Services Industry Training organization, Wellington.

Kell, C, Guy, S, Hastwell, K and Harvey, S (2009). In-house Literacy, Language and Numeracy (LLN) Initiatives in New Zealand Workplaces. Summary Report to the Department of Labour,Department of Labour, Wellington.

Lave, J, and Wenger, E (1991) Situated learning: Legitimate peripheral participation, Cambridge University Press, Cambridge.

McGregor, J and Gray, L (2003) Modern Apprenticeships: Training for the boys? An equal employment opportunities discussion paper, Human Rights Commission, Wellington.

McManus, S and Russell, J (2007) Peer Mentoring Relationships, in Ragins, B and Kram, K, The Handbook of Mentoring at Work, Sage, California, pp 273-298.

Ragins, B, and Verbos, A (2006) Positive Relationships in Action:

Relational mentoring and mentoring schemas in the workplace, in Dutton, J and Ragins, B, eds, Exploring Positive Relationships at Work: Building a theoretical and research foundation, Routledge/Taylor \& Francis, London, pp 91-115.

Ratima, M and Grant, B (2007) Thinking About Differences Across and Within Mentoring,Maori and Indigenous review, vol 3, Peer commentary 1 . 
Vaughan, K (2008) Workplace Learning: A literature review, New Zealand Council for Educational Research, Wellington.

\section{Endnotes}

${ }^{\mathrm{i}}$ Holland, C. On and off the job: learning experiences, connections and implications for LLN, May 2009. JITO: Wellington

ii The role of ITOs in New Zealand is to develop industry qualifications and to arrange and facilitate trainee and apprentice learning.

iii The term 'Cultural Capital' was introduced by Bourdieu (1977) to discuss access to different 'capitals' or advantages afforded by different classes. Here it means advantage in terms of understanding how things are done in a local environment such as the workplace or community. 